
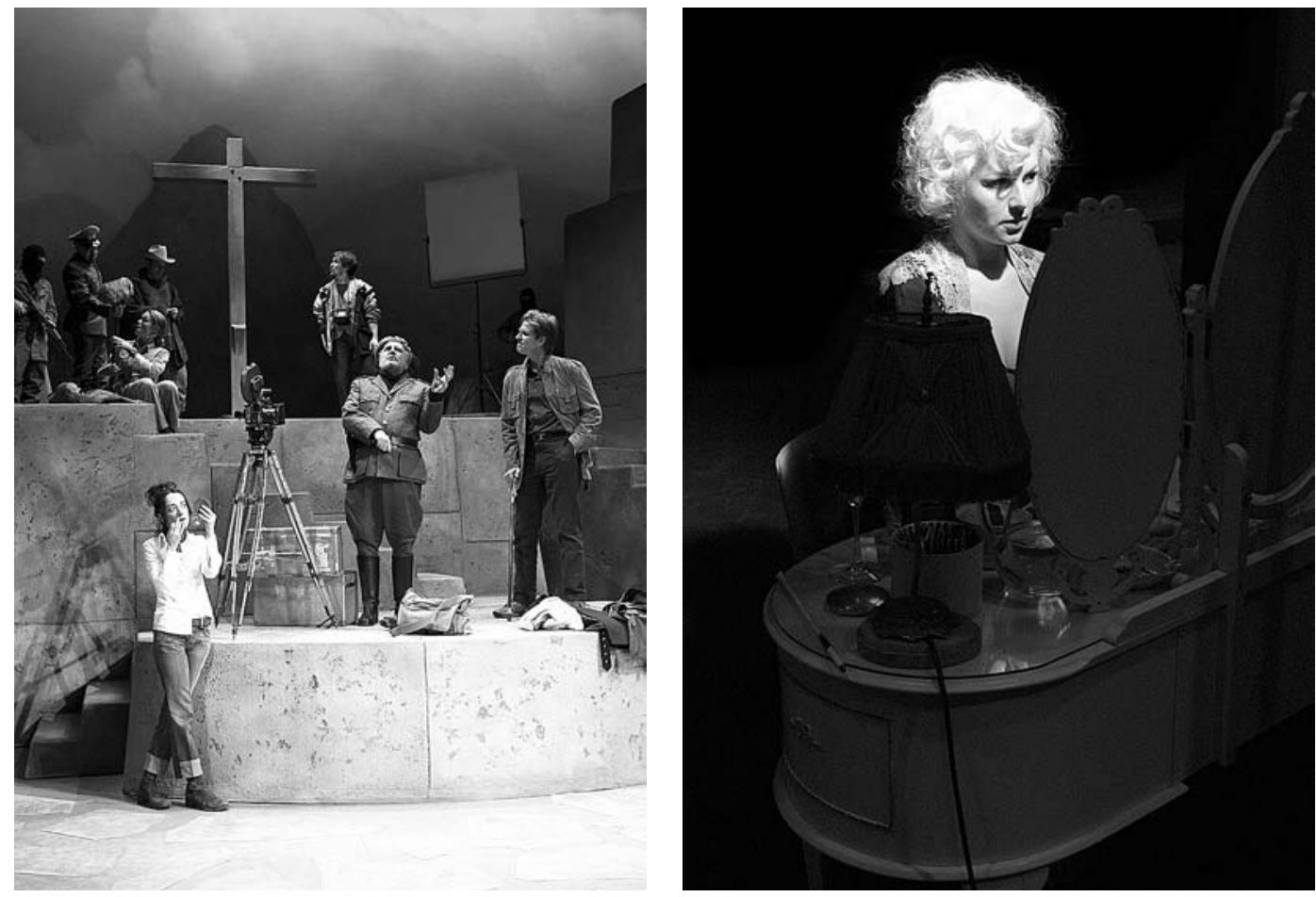

Resurrection Blues, de Arthur Miller, enc. Robert Altman, Old Vic, Londres, 2006 (o elenco, com, entre outros, Maximilian Schell e Matthew Modine), fot. Manuel Harlan.

\title{
Elementos fardados do público
}

\author{
lan Shuttleworth
}

Neste texto, quero assumir a que é muitas vezes considerada a postura tradicional do crítico, ou seja, quero olhar para os dois lados ao mesmo tempo. Julgo que nisto estou justificado. Como vemos muitas vezes em sondagens e estudos de mercado, as respostas podem ser muito diversas dependendo da forma como se coloca a pergunta. $\mathrm{Na}$ questão de saber se os críticos são necessários, não hesito em alinhar com os defensores da prática. Todavia, se considerarmos não a questão imediata, mas o tópico mais vasto colocado pela questão "0 fim da crítica?", sinto-me muito menos optimista. Receio bem que seja possivel em particular no meu próprio campo, o da crítica jornalistica - que ela não sobreviva ao fim da vida de alguns de nós. Espero que me perdoem, então, se algumas das minhas observações ganharem um laivo de lamento pessoal e auto-centrado. Para além disso, as minhas observações incidem quase exclusivamente sobre a crítica jornalistica no Reino Unido. Sei que o meu próprio pais foi mais longe que muitos outros na senda preocupante de que vou falar, mas penso que os desenvolvimentos culturais em questão nos afectarão a todos nós com maior ou menor incidência.

Pondo a questão sem rebuço, a situação é a seguinte: a finalidade da crítica - no sentido do seu objectivo ou propósito - é, na visão de editores de jornais e revistas, a deles próprios e dos que ai pagam publicidade, fazer com que a sua publicação pareça que se preocupam com a cultura. Críticas às artes performativas (excepção feita à música pop e ao rock), bem como às artes visuais e plásticas, arquitectura e design, são, em termos de publicação, "líderes perdedores" impróprios para manchete. 0 nosso trabalho permite aos poderes dominantes, nas nossas publicações, manter uma imagem de comprometimento com o espectro total da vida: material e mental, social e espiritual. Contudo, do ponto de vista editorial, a extensão da cobertura real é um meio estatisticamente feliz: se demasiado pequeno, o sinal de que falo seria demasiado transparente, se demasiado grande, ocuparia muito espaço que podia ser usado de forma mais proveitosa. Assim que a equação custo/benefício apresenta uma solução diferente, então, nas palavras de Liz Imbrie, a foto-jornalista em A história de Filadélfia (The Philadelphia Story), de Philip Barry, "Apertamse mais os cintos nesta temporada". Cada vez mais, também a cultura da celebridade e, em menor grau, a das "notícias que dão manchete" fazem com que a cobertura crítica de um trabalho passe para um segundo lugar relativamente às notícias ou à cobertura da noite de estreia do showbiz - não o trabalho, mas o evento. Às vezes, até acontece que os críticos são contratados por terem um nome que apela aos leitores, mais do que em função de uma competência específica que possam ter no assunto em questão.

Para dar um exemplo da primeira dessas situações: em Setembro de 2004, o Teatro Nacional em Londres apresentou São coisas que acontecem (Stuff Happens), a peça de David Hare sobre o fundo político da guerra no Iraque. 0 jornal Guardian levou à antestreia do espectáculo um grupo considerável de comentadores dos media, políticos trabalhistas e conservadores, um oficial e um inspector de armas das Nações Unidas, para que dessem as suas opiniões sobre a peça. Os seus depoimentos foram publicados no Guardian uma semana antes da estreia a que teve acesso o crítico do próprio jornal, Michael Billington. Durante essa semana, a abordagem do jornal tornou-se, por si só, uma
Two Way Mirror, de Arthur Miller, enc. Mike Miller, Courtyard Theatre, Londres, 2006 (Abi Titmuss), fot. Simon Pugh. $>$ 
"pequena história" para as notícias, e o conselho editorial pediu a Michael Billington que escrevesse um artigo a defender o que o jornal tinha feito. Assim, o crítico de teatro mais respeitado do Reino Unido foi colocado na posição desagradável e francamente absurda de ter de justificar uma política que tinha marginalizado a sua própria opinião e trivializado a sua posição - e reparem, tudo isto antes de ele ter sequer tido a possibilidade de formar uma opinião própria. Foi como se uma defesa do tradicional jantar de Natal tivesse sido encomendada a um peru.

Contudo, pelo menos, Michael Billington desfruta de um conselho editorial que está comprometido em grau muito apreciável com assuntos e acontecimentos culturais. Noutras publicações, a situação é bem mais sombria. Uma das maiores revistas do Reino Unido escolheu para crítico um ex-Secretário de Estado da Defesa que até então não tinha revelado nenhum interesse público visivel pela arte. Uma outra revista contratou um velho colega de universidade do editor, um jornalista provocador que, igualmente, não tinha nunca mostrado grande interesse pela prática teatral, mas tinha confidenciado ao seu amigo que precisava de um emprego. 0 jornal do Reino Unido que mais vende emprega agora como principal crítico de teatro um homem que também escreve cenas parlamentares meio humoristicas e mordazes; não sei se foi por essa razão que o contrataram, mas o resultado é uma torrente de críticas que promovem a agenda política e os preconceitos sociais da linha editorial do jornal, com uma atenção meramente especulativa relativamente ao lado artístico, teatral ou cultural das coisas. Uma submissão tão espalhafatosa da cobertura das artes a uma agenda política é coisa que raramente acontece no mundo democrático. 0 homem é também, tanto quanto sei, o crítico de teatro mais bem pago da imprensa escrita do Reino Unido.

Portanto, se editores e até certo ponto leitores parecem ver os críticos como um acessório de cosmética mais do que uma necessidade, como posso eu levantar-me aqui e afirmar que continuamos a ser verdadeiramente necessários?

Até certo ponto, esta visão pessimista fala "por" mim. 0 que acabei de retratar é uma cultura que, ao trivializar a crítica das artes, trivializou-se e empobreceu-se a si própria. A descrição mais sucinta que encontrei da função da crítica é "explicar a si própria o que é a cultura". Isto é verdade, quer o fórum da crítica sejam os meios de comunicação, quer seja a academia: os nossos específicos modos de discurso podem ser diferentes em função dos leitores a quem nos dirigimos, mas a actividade fundamental e as relações triplas entre assunto, crítica e público são as mesmas. É evidente que não podemos dar explicações cabais; nenhum crítico, nem académico, nem jornalista, pode sequer alguma vez pretender fazê-lo - simplesmente porque as opiniões e perspectivas são as de cada um. Mas podemos informar a cultura sobre o que ela é.

De iqual forma, porém, deve ser claro que por "cultura" não me refiro exclusivamente a qualquer conceito de cultura em sentido restrito ou de "alta cultura": por exemplo, orgulho- me de ter contribuido há alguns anos atrás com um capítulo para um volume escolar sobre a série de televisão Buffy, a caça vampiros (Buffy The Vampire Slayer). Nem precisamos de explicar entre nós que a cultura é um conceito vasto e muito abrangente. 0 que precisamos de fazer, isso sim, é sermos vistos a abranger uma tal latitude na nossa prática.

Há alguns dias atrás, estreou um espectáculo sobre duas peças de Arthur Miller, num dos teatros alternativos de Londres, com o título Espelho de duas faces (Two-Way Mirror). Passaria completamente despercebido no panorama crítico, seguramente eclipsado pela revisitação da Royal Shakespeare Company à peça Bruxas de Salém (The Crucicle), de Arthur Miller, e pela estreia - com encenação de Robert Altman - da versão final revista de Blues da ressurreição (Ressurection Blues), apresentados na mesma semana. Mas um factor fez com que esse pequeno espectáculo fosse aquele a que os meios de comunicação mais populares deram uma maior atenção: a actriz principal é um dos exemplos actuais mais famosos da cultura britânica de celebridades, uma jovem que é famosa apenas por ser muito conhecida, alguém que se tornou uma imagem de cartaz, uma cara conhecida e uma presença permanente em vários programas de televisão simplesmente porque é uma imagem de cartaz, uma cara conhecida, etc. 0 que devemos fazer como críticos numa situação deste género é nunca desdenhá-la por, eventualmente, termos ideias feitas sobre o seu estatuto cultural, nem tratá-la como uma espécie de coisa exótica no teatro, uma visitante vinda de uma dimensão cultural paralela.

Parte do problema aqui é que os que estabelecem o contexto no qual operam os críticos de imprensa - editores e proprietários dos nossos jornais, rádios, televisões, etc. - tendem a ser apanhados nesta noção polarizada de cultura. Mesmo no que podiamos considerar os jornais e revistas de qualidade, há uma aquiescência (embora possa ser inconsciente) na assunção de que a cultura popular é talvez não totalmente distinta da "alta cultura", mas um campo mais adequado ou, pelo menos, mais proveitoso para cobrir jornalisticamente. 0 que nós, críticos, temos de fazer é implicitamente refutar isso no que escrevemos: forjar uma ligação tripla entre o assunto imediato, os mais vastos contextos sociais e históricos em que se integra e os nossos vários públicos.

E isto é algo que, em muitos casos, temos de fazer de forma velada, ou pelo menos por nós próprios. Um dos equivocos mais difundidos entre os artistas de teatro é pensar que os críticos têm um dever para com o teatro de ser "apoiantes" ou "construtivos", ou algum outro termo que na prática significa que só deveriamos praticar o tipo e a extensão de crítica que esses artistas estão preparados para ouvir. Há um sentimento de que a crítica acerada é de algum modo uma traição aos nossos camaradas, aos nossos "iguais companheiros de profissão". E este sentimento é disparatado. Com toda a franqueza, acho que jamais os artistas chegarão a compreender o facto simples de que "nós não trabalhamos na mesma área que eles". Eles 


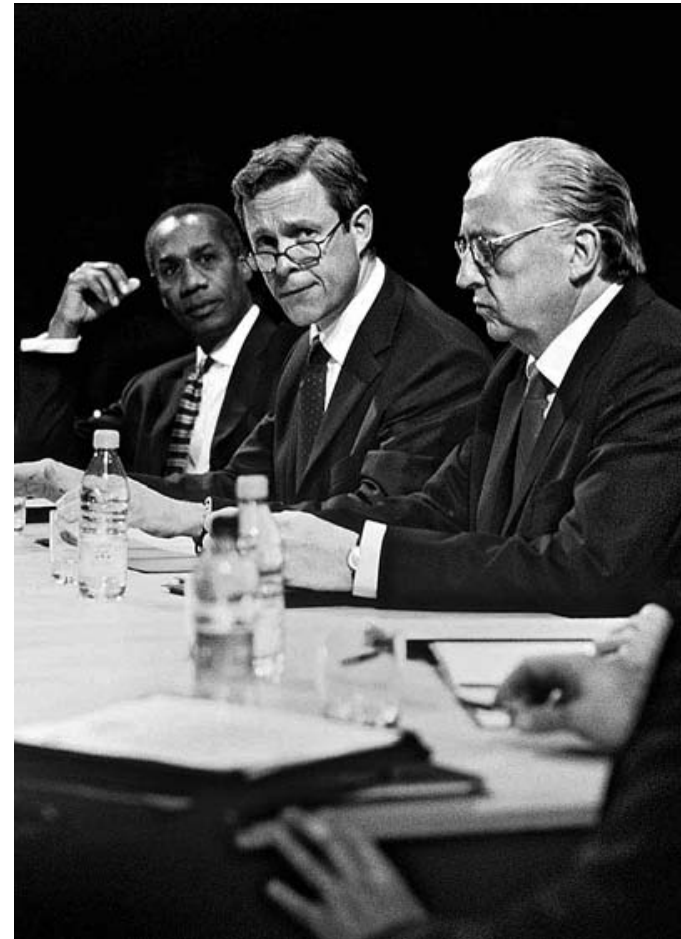

trabalham no teatro, e nós no jornalismo. 0 teatro pode ser - é-o quase sem excepção - uma paixão impetuosa para nós, nas não é aí que trabalhamos. Podemos ser tipos teatrais e/ou críticos por vocação, mas, pela profissão, somos jornalistas. Ai está, como vêem, fiquei tão inflamado com este engano que acabei por o negar quatro vezes de seguida.

E este é o contexto em que temos de fazer o que nos pedem para fazer: a nossa profissão, por um lado, e a nossa paixão, pelo outro, e essas exigências podem muitas vezes entrar em conflito entre si. Temos de encontrar a quadratura do círculo entre a análise intelectual e a reportagem. Temos de tornar claro que a arte é notícia não porque tem um nome específico, um rosto ou outra qualquer imagem de marca presa a ela, mas nos seus próprios termos; que é uma parte integrante e vital de como vivemos e nos compreendemos, tanto individualmente, como enquanto sociedade.

E ter de fazer isto de uma forma que atraia a cumplicidade dos nossos leitores e também dos nossos chefes de redacção: temos de os seduzir a que aceitem isto como axiomático, e disfarçar a possibilidade de que possamos estar a desafiar os seus preconceitos sobre a arte. Se conseguirmos levá-los a aceitar, pelo menos durante o tempo em que nos lêem, que a arte é um elemento essencial, mais do que um luxo marginal, então há uma hipótese de que possam pensar nisso também noutras ocasiões.

Quero tornar claro que não estou a sugerir que esta é uma exigência impossível; pelo contrário, deve não apenas ser atingivel, devemos mesmo torná-la numa "rotina". Este é o panorama mediático pelo qual temos de caminhar, indicando as direcções e sentidos que pudermos, informando a cultura sobre ela própria. Não podemos ser tudo para todas as pessoas, é evidente: o que podemos é comprometermo-nos numa frente "suficientemente" vasta. Há alguns anos, ouvi de um estudante uma ideia brilhante - ainda que dita de forma desajeitada: a arte, disse ele ( $e_{1}$ portanto, a nossa crítica) não é sobre a forma de chegar
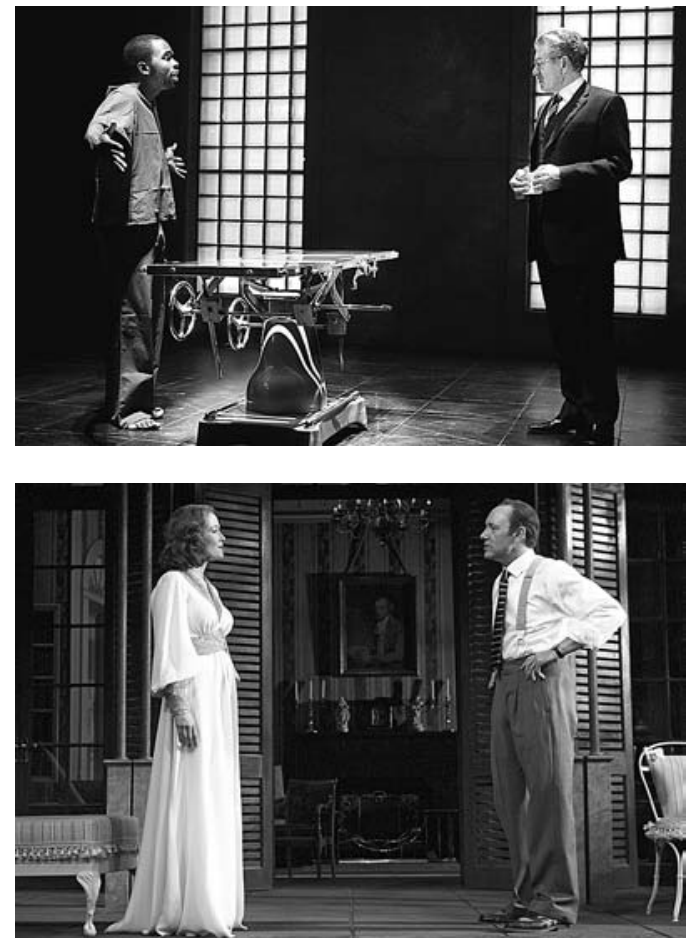

The Cut,

de Mark Ravenhill, enc. Michael Grandage, Donmar Warehouse, Londres, 2006 (Jimmy Akingbola e lan McKellen), fot. Robert Workman.

ao tipo certo de pessoas; é antes chegar ao tipo errado de pessoas e torná-las o tipo certo.

Julgo que a maior vitalidade da crítica jornalistica é demonstrada pela crítica do dia seguinte. Com certeza, a exigência de escrever várias centenas de palavras de uma opinião totalmente formada sobre um espectáculo talvez uma hora depois de descer a cortina pode ser um convite ao desastre. Mas também é a manifestação mais directa da arte enquanto noticia: o relato de um acontecimento que mal acabou, uma peça de escrita que junta o registo factual ao comentário e uma dose de análise de resposta rápida. Pode ser possível prepararmo-nos bem para isso em termos de leituras prévias ou de refrescar as nossas capacidades mentais: a nossa resposta é fundamentalmente imediata.

Mesmo quando não somos constrangidos por prazos eu pessoalmente tento escrever as minhas críticas "nessa mesma noite", porque acredito na força da crítica do dia seguinte. Isto pode em parte dever-se ao facto de uma abordagem destas condizer com a minha capacidade de memória e a minha preguiça congénita. A minha justificação vem de ter estudado Direito antes de ter sequer imaginado tornar-me um crítico de arte. Nos primeiros tempos da força policial, os agentes não tinham um poder - de prender ou deter alguém - maior do que qualquer outro cidadão; estavam simplesmente comprometidos profissionalmente a exercer esses poderes comuns. Este estatuto foi

admiravelmente resumido por um juiz oitocentista quando descreveu um polícia, neste sentido, como "um elemento fardado do público".

Tento abordar a maior parte da crítica que escrevo como, por assim dizer, um elemento fardado do público espectador. A minha opinião está apoiada em vinte anos de experiência, tendo visto vários milhares de produções e escrito mais de um milhão de palavras sobre elas. Mas a minha estatura própria não é maior do que a de qualquer espectador. Por outras palavras, acho que a própria pluralidade e provisoriedade que tanto preocupam alguns
Philadelphia Story, de Philip Barry enc. Jerry Zaks, Old Vic, 2005 (Jennifer Ehle e Kevin Spacey), fot. Manuel Harlan. 
de nós são, de facto, uma força. Não podemos fingir que oferecemos a última palavra sobre o espectáculo: o que podemos fazer, ao reconhecer o nosso lugar num debate alargado e contínuo, é ajudar a que o debate se prolongue até à próxima palavra, e a uma outra, e por ai fora.

É o mesmo que eu escrevi acima sobre o desconforto de artistas com o que dizemos às vezes: não interessa só ouvir pessoas cujas opiniões sabemos não levantarem problemas. A cibernética, o estudo científico da comunicação, define "informação" como o conjunto de imprevisibilidades numa mensagem. Se só a embebemos, se não nos faz parar para pensar, então ai não há verdadeira informação. E passa-se o mesmo com a crítica: não podemos apenas emitir juizos, temos de os fundamentar na argumentação. Como se diz na pergunta típica de um exame numa escola britânica: "Dê razões para a sua resposta" (tanto quanto o espaço o permite, é evidente!). E essas razões têm de ser facilmente compreensiveis pelos leitores e, todavia, têm de ser imprevisiveis e informativas. Temos, de cada vez que escrevemos, de ganhar e reconquistar o privilégio de sermos ouvidos. A liberdade de expressão é um direito, mas ser "ouvido"... é um privilégio.

Isto leva-me a um outro aspecto do papel do crítico de jornal. Parece-me incontestável que devemos abraçar as possibilidades dos novos media para alargarmos o discurso. A "blogoesfera", a vasta nebulosa dos diários, revistas e comentários na Internet - geralmente de autopublicações, no geral interactivas - tornou-se para milhões de pessoas o seu primeiro ou mais fiável canal de informação e discussão social, política e cultural. E, como digo, esta abertura e democratização deve seguramente ser olhada como uma coisa boa.

Todavia, o que falta nesta altura à blogoesfera na sua evolução são mecanismos de autoridade. Como estou certo que todos nós já passámos por essa experiência quando procuramos informação sobre um assunto particular através do Google, pode ser bastante confuso saber quais as fontes que vale a pena seguir. É isto que se relaciona com a minha ideia sobre o estatuto dos críticos: a autoridade não é inerente à função, ganha-se, é-Ihe conferida. E os novos modos da crítica nos novos media não existem há tanto tempo assim que lhes permita ter estruturas que lhes confiram autoridade. Não é simplesmente uma questão de contabilizar as consultas a um sítio da Internet, do mesmo modo que a autoridade de um jornal não deriva necessariamente do número de exemplares em circulação nem podemos usar como índices crediveis o volume ou intensidade das respostas (som de retorno interactivo), o número de ocorrências de um sítio em links publicados noutros sítios da Internet, ou (Deus nos livre!) os indices de presença no Google. Reputação, reputação, reputação: é tão inatingivel nesta área como em qualquer outra. Mas ainda não desenvolvemos o tipo certo de "radar de reputação" para navegar com confiança pela blogoesfera. Havemos de o fazer (embora seja preciso coragem para alguém profetizar sobre os desenvolvimentos da Internet mesmo para os próximos cinco anos, como qualquer bancarrota da dot-com ou qualquer evangelista da realidade virtual vos dirá). Mas ainda não o fizemos.

0 que significa que, por enquanto, a combinação do imediatismo relativo e da autoridade conferida no debate cultural continua a encontrar o seu melhor exemplo na crítica jornalística. Um trabalho como este pode enriquecer a experiência do consumo, quer no papel, quer no palco. Contudo, a sua função principal não é a de agir como adjuvante da experiência de ler ou ver uma peça particular. Relata o acontecimento e informa o discurso mais vasto de que o trabalho e a sua recepção se relacionam como partes componentes de um todo.

Uma última questão: há cerca de um ano, dei inadvertidamente origem a uma tempestade na chávena de chá do jornalismo de teatro britânico. Observei numa coluna de uma revista que agora edito, Theatre Record, que alguns críticos são já de uma certa idade e que isso era parte do problema. Para meu espanto, isto foi citado em várias páginas de notícias e de boatos, e era referido como se eu tivesse lançado um apelo amargo para que os críticos mais velhos se reformassem ou dessem lugar, por exemplo, a mim.

Eu não disse nada disso, é evidente; o que eu estava a sublinhar era que, enquanto as possibilidades dadas à crítica jornalística continuarem a diminuir, então as gerações e fileiras de críticos continuam no activo, e são menores as oportunidades para que novas gerações entrem em campo. Nesse aspecto, talvez seja melhor que o sector dos novos media encontre os seus mecanismos de conferir autoridade muito rapidamente; de contrário, muito em breve não haverá saídas nem estruturas fora da academia para jovens críticos aprenderem a sua arte e ocuparem o seu lugar na conversação cultural dominante. Resumindo, os editores não estão a investir no bem-estar a longo prazo dos meios de comunicação como um todo. Dentro de vinte ou trinta anos, podem ver-se sem os críticos de que precisam. E o que é mais horrivel é que podem nem sequer notar, nem importar-se com isso.

Estas são todas observações muito provisórias. Tenho consciência de que em muitos aspectos estou a condescender com um fenómeno muito conhecido de olhar para trás, para uma idade de ouro mítica, de há uma ou duas gerações, neste caso um tempo em que o espaço para publicação, a verba e o respeito eram alegadamente muito maiores. Contudo, hoje, mesmo se damos conta de estarmos a competir na atenção com as coisas efémeras mais insípidas, estamos também envolvidos numa troca de opiniões e ideias muito mais dinâmica. Já não nos pronunciamos e julgamos: argumentamos, advogamos e aconselhamos. E ouvimos quando os outros fazem o mesmo. Ajudamos a explicar a cultura a si própria, não como parte de um debate dentro de uma cidadela, mas na totalidade da conversação nacional e global em curso.

Tradução de Maria Helena Serôdio 